\title{
MYCN promotes neuroblastoma malignancy by establishing a regulatory circuit with transcription factor AP4
}

\author{
Chengyuan Xue ${ }^{1, *}$, Denise M.T. Yu ${ }^{1, *}$, Samuele Gherardi ${ }^{2}$, Jessica Koach ${ }^{1}$, Giorgio \\ Milazzo $^{2}$, Laura Gamble ${ }^{1}$, Bing Liu ${ }^{1}$, Emanuele Valli ${ }^{1}$, Amanda J. Russell ${ }^{1}$, Wendy \\ B. London ${ }^{3}$, Tao Liu ${ }^{1}$, Belamy B. Cheung ${ }^{1}$, Glenn M. Marshall ${ }^{1,4}$, Giovanni Perini ${ }^{2,5}$, \\ Michelle Haber ${ }^{1, \#}$, Murray D. Norris ${ }^{1,6, \#}$ \\ ${ }^{1}$ Children's Cancer Institute, Lowy Cancer Research Centre, University of New South Wales, Sydney, Australia \\ ${ }^{2}$ Department of Pharmacy and Biotechnology, University of Bologna, Bologna, Italy \\ ${ }^{3}$ Boston Children's Hospital and Dana-Farber Cancer Institute, Harvard Medical School, Boston, MA, USA \\ ${ }^{4}$ Kids Cancer Centre, Sydney Children's Hospital, Sydney, Australia \\ ${ }^{5}$ CIRI Health Sciences and Technologies University of Bologna, Bologna, Italy \\ ${ }^{6}$ University of New South Wales Centre for Childhood Cancer Research, Sydney, Australia \\ *Joint first authors \\ \#Joint senior authors
}

Correspondence to: Murray D. Norris, email: MNorris@ccia.unsw.edu.au Michelle Haber, email: MHaber@ccia.unsw.edu.au

Keywords: neuroblastoma, cancer, MYCN oncogene, TFAP4, cell migration

Received: January 11, 2016

Accepted: June 16, 2016

Published: July 19, 2016

\section{ABSTRACT}

Amplification of the MYCN oncogene, a member of the MYC family of transcriptional regulators, is one of the most powerful prognostic markers identified for poor outcome in neuroblastoma, the most common extracranial solid cancer in childhood. While MYCN has been established as a key driver of malignancy in neuroblastoma, the underlying molecular mechanisms are poorly understood. Transcription factor activating enhancer binding protein-4 (TFAP4) has been reported to be a direct transcriptional target of MYC. We show for the first time that high expression of TFAP4 in primary neuroblastoma patients is associated with poor clinical outcome. siRNA-mediated suppression of TFAP4 in MYCN-expressing neuroblastoma cells led to inhibition of cell proliferation and migration. Chromatin immunoprecipitation assay demonstrated that TFAP4 expression is positively regulated by MYCN. Microarray analysis identified genes regulated by both MYCN and TFAP4 in neuroblastoma cells, including Phosphoribosyl-pyrophosphate synthetase-2 (PRPS2) and Syndecan-1 (SDC1), which are involved in cancer cell proliferation and metastasis. Overall this study suggests a regulatory circuit in which MYCN by elevating TFAP4 expression, cooperates with it to control a specific set of genes involved in tumor progression. These findings highlight the existence of a MYCN-TFAP4 axis in MYCN-driven neuroblastoma as well as identifying potential therapeutic targets for aggressive forms of this disease.

\section{INTRODUCTION}

The MYC family of proto-oncogenes play important roles as transcriptional regulators in vital cellular functions [1]. The most well-characterised member of the family, MYC, is frequently deregulated in adult cancers $[2,3]$. In neuroblastoma, the most common extracranial solid tumor of childhood accounting for approximately 15\% of all childhood cancer related deaths, amplification of the $M Y C N$ oncogene in tumors represents one of the most powerful prognostic markers yet identified for this malignancy [4]. Although MYCN amplification and consequent overexpression has been established as a key driver of malignancy in $M Y C N$-amplified high-risk 
neuroblastoma, the exact mechanisms by which MYCN contributes to the aggressive phenotype of neuroblastoma remain largely unknown [4]. Developing a greater understanding of some of the underlying mechanisms of MYCN-mediated neuroblastoma progression is important for identifying genes responsible for tumor progression as well as potential molecular therapeutic targets.

TFAP4 is a member of the basic helix-loop-helix transcription factors that recognize the E-box sequence CAGCTG in the promoters of target genes [5], and has been shown to be a direct transcription target of MYC [6]. Recently, there has been increasing evidence that TFAP4 plays important roles in human cancer development and progression and in particular, it has been found to be a direct inducer of epithelial-mesenchymal transition (EMT) that contributes to metastatic processes in colorectal cancer [7]. In addition, elevated TFAP4 expression significantly correlates with tumor progression and poor prognosis in a number of malignancies, including colorectal cancer $[7,8]$, gastric cancer [9] and non-small cell lung cancer [10]. Conversely, down-regulation of this transcription factor blocks proliferation of human gastric cancer cells [9] and inhibits metastasis of colorectal cancer cells in mice [7]. Therefore as a MYC transcriptional target, TFAP4 may play a critical role in cancer cells in concert with deregulated MYC, by coordinating the expression of specific genes that are essential for tumor progression. In this study, the relevance of TFAP4 in the context of MYCN-driven neuroblastoma was investigated.

\section{RESULTS}

\section{TFAP4 is directly regulated by MYCN}

Since TFAP4 has been reported to be a direct transcriptional target of MYC in adult breast cancer cells [6], we investigated whether a similar relationship exists between TFAP4 and MYCN in neuroblastoma by performing expression analysis following knockdown of $M Y C N$ in $M Y C N$-amplified neuroblastoma cell lines BE(2)-C, CHP-134 and IMR-32. We observed that TFAP4 protein levels were markedly downregulated following MYCN depletion (Figure 1A, Supplementary Figure S1A). Similar results were demonstrated in $M Y C N$-inducible SH-EP/TET21/N human neuroblastoma cells following tetracycline treatment (Figure 1B, Supplementary Figure S1B). Additionally, increased MYCN expression was found to correlate with increased TFAP4 protein and RNA expression in SH-EP/S1 cells stably overexpressing $M Y C N$ compared to SH-EP/EV controls (Figure 1C, Supplementary Figure S1B).

To assess whether MYCN is a direct transcriptional regulator of TFAP4, quantitative chromatin immunoprecipitation (qChIP) assays were performed in BE(2)-C and SH-EP/TET21/N cells. MYC has been reported to bind to three of four canonical E-boxes
(CACGTG) in the first intron of TFAP4 [6]. Using MYCN and Max antibodies, we confirmed that both MYCN and Max strongly bound to these E-box motifs (amp A+B), but not to a control region (amp C) located in intron 6 of TFAP4 (Figure 1D-1E). Interestingly, differences in the relative ChIP enrichments observed between $\mathrm{BE}(2)-\mathrm{C}$ and $\mathrm{SH}-\mathrm{EP} / \mathrm{TET} 21 / \mathrm{N}$ cells reflect the intrinsic level of MYCN expressed in these cells which is markedly higher in $\mathrm{BE}(2)-\mathrm{C}$ than SH-EP/TET21/N, even when the latter are induced to express MYCN. The fact that MYCN binding is consistently observed in both cell lines for E-box A but only in BE(2)-C for E-box B may be explained by the variability of fragmented DNA size used for the ChIP assays. Nevertheless, these observations are consistent with the accepted notion that MYC activity is exerted nearby the transcription start site, and that maximal binding of MYC to promoters occurs at the transcription start site and fades with distal E-box elements. Specificity of the MYCN binding to the E-box motifs was supported by a striking reduction of $\mathrm{MYCN}$ binding to DNA when MYCN expression was repressed (Figure 1E). Collectively, these data indicate that TFAP4 is a direct transcriptional target of MYCN in neuroblastoma.

\section{TFAP4 promotes cell growth in neuroblastoma}

We next investigated whether TFAP4 promotes cell growth in $M Y C N$-amplified neuroblastoma. We observed that knockdown of TFAP4 in both $M Y C N$ amplified neuroblastoma $\mathrm{BE}(2)-\mathrm{C}$ cells, and $\mathrm{SH}-\mathrm{EP} /$ $\mathrm{S} 1$ neuroblastoma cells (stably overexpressing MYCN) resulted in a marked decrease in colony forming ability of these cells (Figure 2A), and cell cycle arrest at G1 and S phases (Figure 2B, Supplementary Figure S1C), while $\mathrm{BE}(2)-\mathrm{C}$ cells also demonstrated a decrease in the cell population at $\mathrm{G} 2 / \mathrm{M}$ phase. We next investigated potential alterations in cyclin-dependent kinase inhibitor levels and a marked upregulation of $\mathrm{p} 27^{\mathrm{Kip} 1}(\mathrm{Cdkn} 1 \mathrm{~b})$ was observed in both cell lines (Figure 2C). These results show that suppression of TFAP4 leads to an increase in cyclindependent kinase inhibitor levels, which may contribute to the reduced growth phenotype of neuroblastoma cells.

\section{TFAP4 is required for cell migration in MYCN- overexpressing neuroblastoma cells}

In addition to a growth inhibitory phenotype, we observed that TFAP4 knockdown in BE(2)-C cells also led to reduced cell motility compared with control siRNA transfected cells, as measured by wound closure (Figure 3A) and transwell migration assays (Figure 3B). To confirm the role of TFAP4 in neuroblastoma cell migration, we next performed cell migration assays after transiently overexpressing TFAP4 in MYCN non-amplified cell lines (SH-SY5Y and SK-N-FI), which express relatively low levels of both MYCN and TFAP4. In both SH-SY5Y 
and SK-N-FI, overexpression of TFAP4 demonstrated enhanced migratory ability compared to empty vectortransfected controls (Figure 3C, Supplementary Figure S2A). To further evaluate the importance of TFAP4 in MYCN-driven neuroblastoma migration, SHSY5Y neuroblastoma cells were transiently transfected initially with a $M Y C N$-overexpressing construct, followed 24 hours later by TFAP4 or control siRNA. While an increase in migration compared to controls was observed with MYCN overexpression, TFAP4 depletion abrogated this effect, restoring migration to similar levels as control siRNA-treated cells (Figure 3D). Taken together, these data suggest that TFAP4 is required for the MYCN-driven neuroblastoma migration phenotype.

\section{TFAP4 gene expression is associated with poor clinical outcome in primary neuroblastoma}

To determine whether TFAP4 has prognostic significance in primary neuroblastoma, we analysed TFAP4 gene expression and its association with clinical outcome in an expression array dataset from a prospectively accrued primary neuroblastoma cohort of 649 patients (Oberthuer cohort) [11]. TFAP4 expression was strongly associated with both poor event-free survival (EFS) and overall survival (OS) when samples were dichotomised using the upper decile as a cut point (Figure 4A). These results were validated in another cohort of 208 patient samples from Children's Oncology Group (COG) using qPCR-based
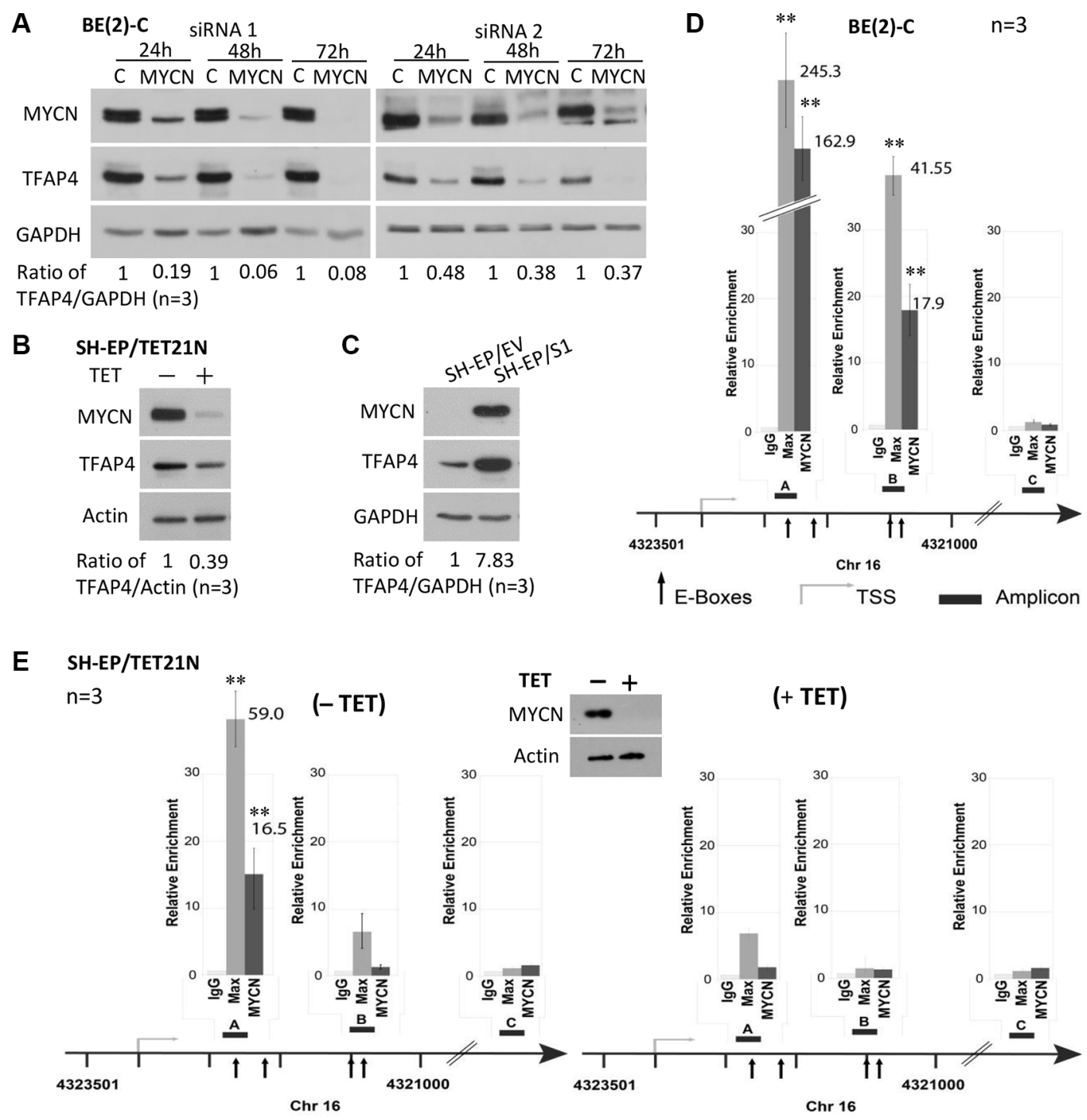

Figure 1: TFAP4 is regulated by MYCN in neuroblastoma cells. Suppression of $M Y C N$ resulted in down-regulation of TFAP4 in BE(2)-C cells (A). TFAP4 expression levels paralleled MYCN expression in SH-EP/TET21/N cells (MYCN Tet-Off system, 24 hours) (B) and in neuroblastoma SH-EP/S1 cells constitutively expressing exogenous MYCN compared with SH-EP/EV controls (C). GAPDH or Actin served as protein loading controls on Western blot. Quantitative ChIP assays in BE(2)-C cells (D) and SH-EP/TET21/N cells expressing MYCN (E) or treated with tetracycline (TET) for $48 \mathrm{~h}$ (E) demonstrated that MYCN directly binds to two E-box sites (amp A and B) located in the first intron of the TFAP4 gene, but not the control region (amp C). Western blot confirmed repression of MYCN expression with tetracycline treatment (E, inset). Mean $\pm \mathrm{SE}(n=3)$. amp, amplicon; TSS, transcription start site. $* * P<0.01$. 
methodology (Figure 4B). However, multivariate analysis, taking into account patient age, stage and MYCN status, showed that TFAP4 was not an independent prognostic marker (data not shown), suggesting its upregulation could be largely dependent on $M Y C N$ overexpression.
Concordantly, TFAP4 gene expression levels were significantly higher in $M Y C N$-amplified tumors by comparison with non-MYCN amplified tumors (Figure 4C) and positively correlated with $M Y C N$ expression in both datasets (Supplementary Figure S2B).

A BE(2)-C
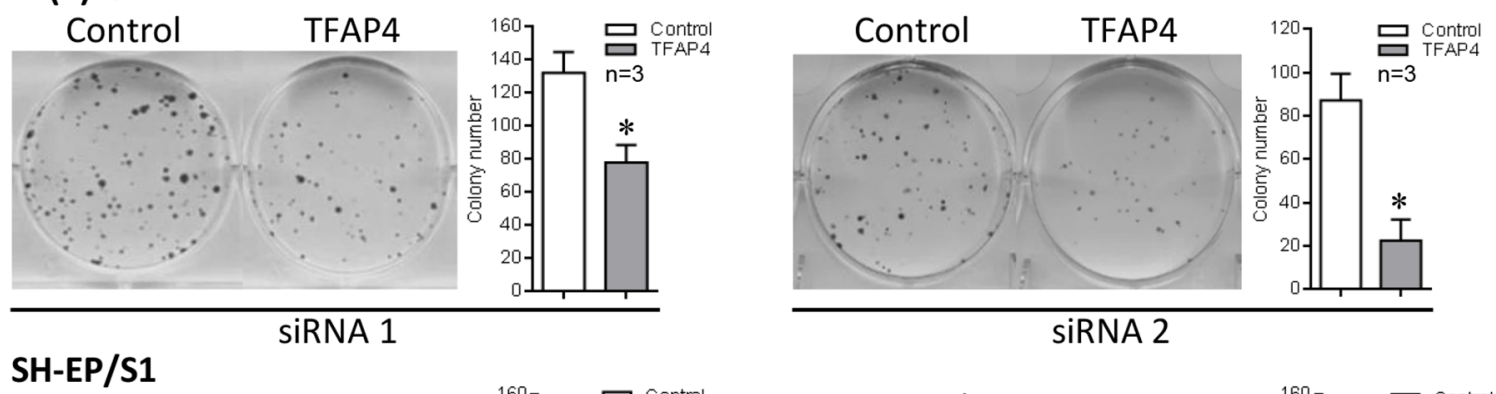

SiRNA 1

siRNA 2
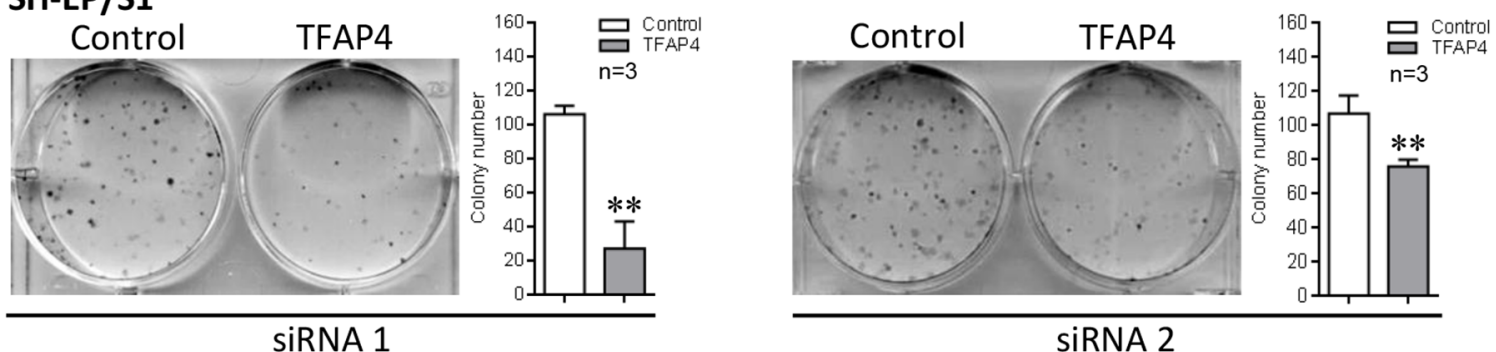

B BE(2)-C

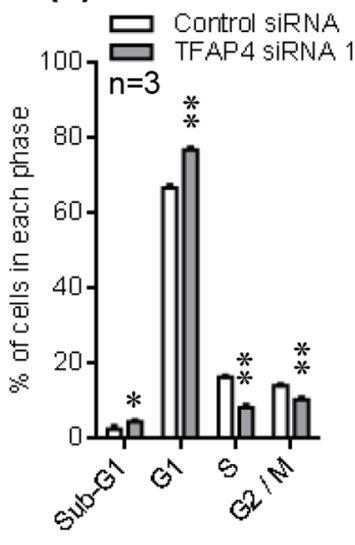

C

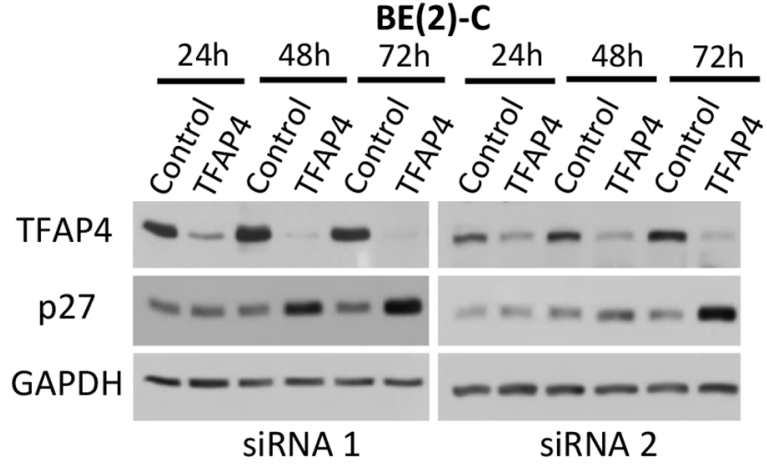

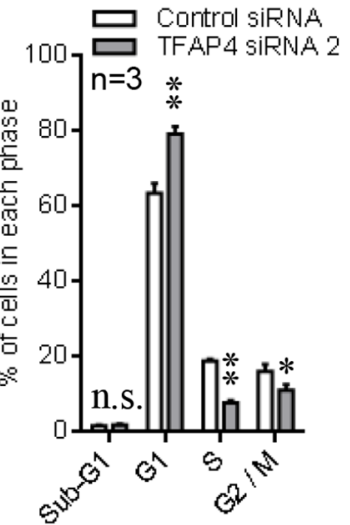

BE(2)-C
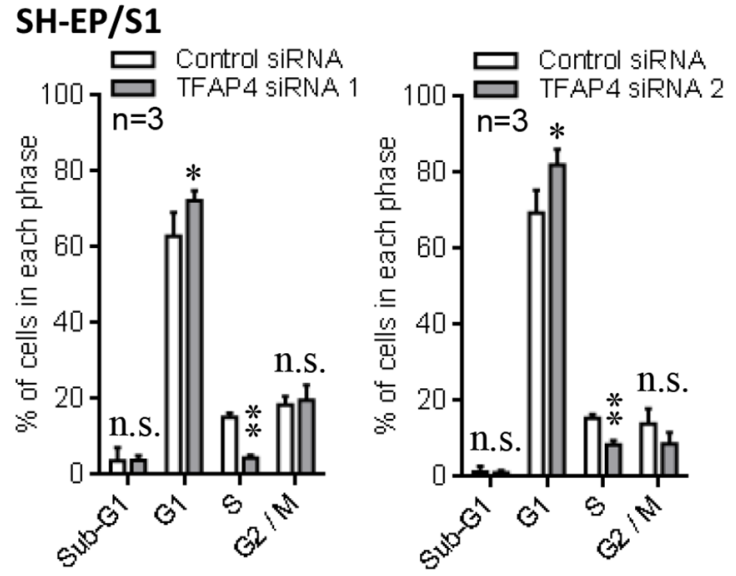

SH-EP/S1

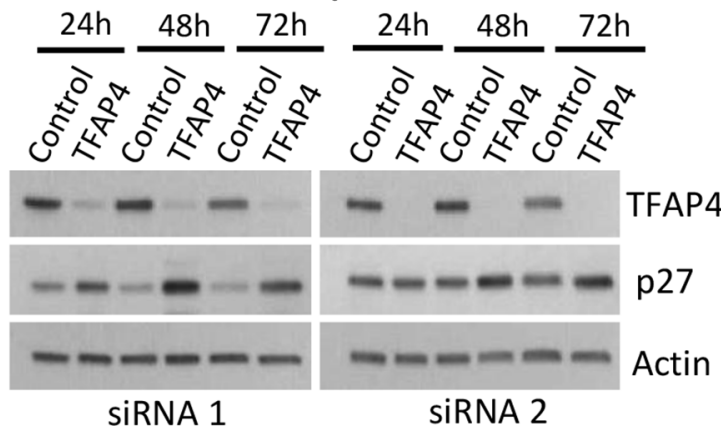

Figure 2: Inhibition of neuroblastoma cell growth following knockdown of TFAP4. Knockdown of TFAP4 reduced colony forming ability in $M Y C N$-amplified BE(2)-C and $M Y C N$-overexpressing SH-EP/S1 cells (A). Cell cycle analysis showed strong G1/S arrest $48 \mathrm{~h}$ after TFAP4 depletion (B). Western blots showed increased p27 in TFAP4-depleted BE(2)-C and SH-EP/S1 (C). ${ }^{*} P<0.05, * * P<0.01$, n.s.- not statistically significant. 
Table 1: Genes showing two-fold differential expression 30 hours after depletion of $M Y C N$ or TFAP4 by siRNA knockdown in BE(2)-C neuroblastoma cells

Gene symbol

Function

Genes downregulated by $M Y C N \&$ TFAP4 siRNA

\begin{tabular}{|l|l|}
\hline PRPS2 & Synthesis of purines and pyrimidines \\
\hline SDC1 & Cell proliferation, migration and cell-matrix interactions \\
\hline SLC7A6 & Amino acid transport \\
\hline Genes upregulated by MYCN and TFAP4 siRNA & \multicolumn{2}{|l|}{} \\
\hline CYLD & Deubiquitination, inhibition of NF-kappa-B and HDAC6 \\
\hline MFSD6 & Transmembrane transport of small solutes \\
\hline FMR1 & Translational repression \\
\hline CSGALNACT2 & Elongation during chondroitin sulfate synthesis \\
\hline DENND5B & Promotes the exchange of GDP to GTP \\
\hline SSU72 & Dephosphorylation of RNA polymerase II C-terminal domain \\
\hline LCORL & Spermatogenesis, association with adult height \\
\hline FAM73A & Uncharacterized, likely responsible for obesity \\
\hline C19orf12 & Uncharacterized, mutation found in neurodegeneration \\
\hline OIP5-AS1 & Antisense RNA to OIP5 gene \\
\hline COPS8 & positive regulation of E3 ubiquitin ligases \\
\hline LOC100499177 (uncharacterized gene) & Uncharacterized \\
\hline
\end{tabular}

\section{Identification of genes regulated by $\mathrm{MYCN}$ through TFAP4}

Both MYCN and TFAP4 are known to be involved in regulation of important cell biological processes such as proliferation and migration $[7,12]$. Thus, in order to identify a subset of genes that may be responsible for mediating the effects of MYCN and TFAP4, we performed expression array analyses of differential gene expression in $\mathrm{BE}(2)-\mathrm{C} 30 \mathrm{~h}$ post-transfection with either $M Y C N$ or TFAP4 siRNA (GEO repository accession no. GSE74626). This relatively early timepoint was selected for gene expression analysis to identify direct target genes of both MYCN and TFAP4. Using a two-fold cut-off, the results showed that $M Y C N$ depletion resulted in downregulation of 98 genes out of a total of 20066 genes $(0.49 \%)$, and three of these genes (3.06\%), PRPS2, SDC1 and SLC7A6, were also downregulated with TFAP4 depletion (Supplementary Figure S2C), indicating that these genes were positively regulated by both MYCN and TFAP4. $M Y C N$ depletion also resulted in upregulation of 127 genes $(0.63 \%)$, with 12 of these genes $(9.45 \%)$ also upregulated following TFAP4 depletion, indicating that these genes were negatively regulated by the two transcription factors. The number of genes identified using a two-fold cut-off following MYCN siRNA-mediated inhibition $30 \mathrm{~h}$ posttransfection, was similar to that found in a previous study in neuroblastoma using this time point [13]. In addition, no genes were found to be both upregulated by $M Y C N$ depletion and downregulated by TFAP 4 depletion, or vice versa (Supplementary Figure S2C), which meant that TFAP4 and MYCN did not regulate gene expression in opposing directions.

To confirm differential expression of these genes (Table 1), qPCR was performed on MYCN- and TFAP4depleted BE(2)-C cells except for the uncharacterized gene LOC100499177 (due to unavailability of TaqMan ${ }^{\circledR}$ assay). Loss of MYCN correlated with decreased expression of TFAP4 as well as the three positively regulated genes PRPS2, SDC1 and SLC7A6, and increased expression of the negatively regulated genes CYLD (Cylindromatosis), MFSD6, FMR1, CSGALNACT2, DENND5B, SSU72, LCORL, FAM73A and C19orf12 at $48 \mathrm{~h}$ post-transfection (Table 1). Expression of OIP5-AS1 was slightly increased after $M Y C N$ depletion but not statistically significant, and expression of COPS 8 was unchanged (Figure 5A). For TFAP4 depletion, the qPCR data for every single gene tested was consistent with the microarray findings (Figure 5B). Thus, 12 out of the 15 differentially regulated genes identified in the expression array analyses were verified by qPCR.

\section{PRPS2 and SDC1 are directly regulated by MYCN and TFAP4}

It has been demonstrated in the literature that both MYCN and TFAP4 are effective at both activation and repression of target genes [7, 14]. Although most of our identified candidate genes were repressed by MYCN and TFAP4 we decided to focus on the positively regulated 
genes for essentially two reasons. Firstly, MYCN negative regulation of target genes is not well defined and occurs either through interaction with other accessory transcription factors or through secondary mechanisms, as we have described [15]. Secondly, and more importantly, our interest is directed towards the identification of genes whose inhibition makes them potentially valuable targets for development of new anticancer therapies. We therefore chose to first examine the roles of PRPS 2 and SDC1 that have been associated with rapid tumor progression and
A

$\mathrm{Oh}$

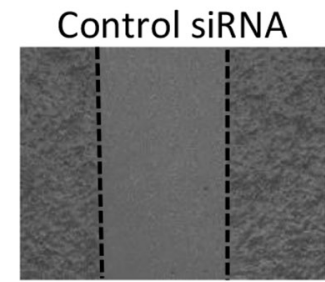

$22 \mathrm{~h}$

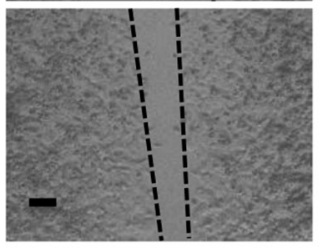

BE(2)-C
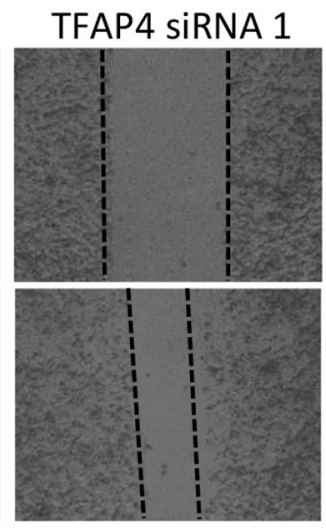
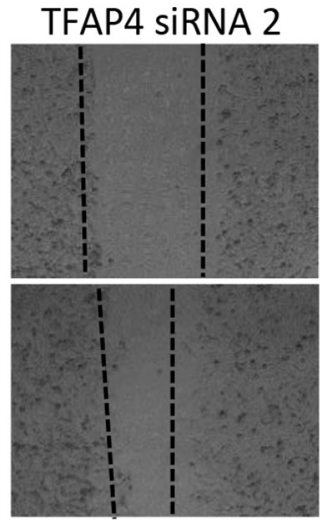

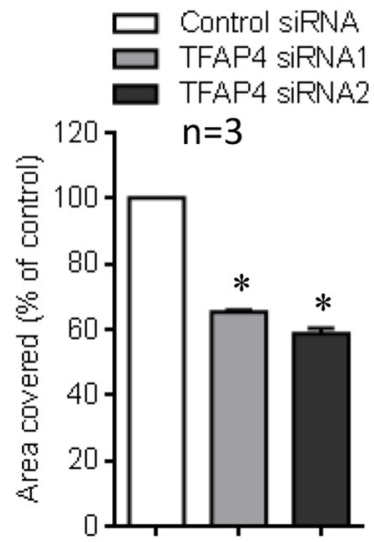

B $\quad B E(2)-C$

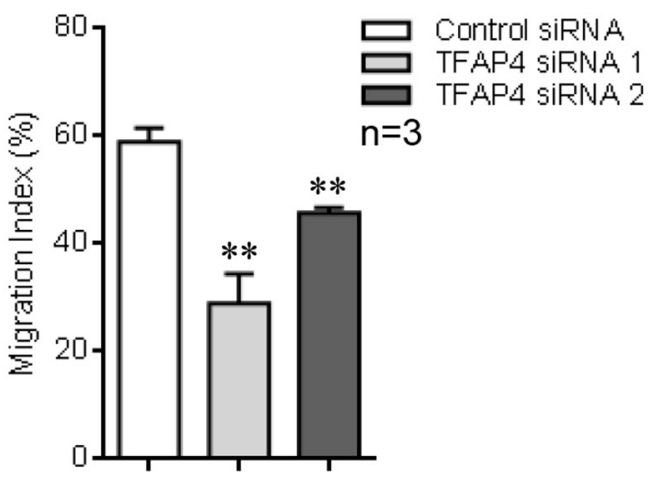

D SH-SY5Y

\section{SH-SY5Y}

Plasmid
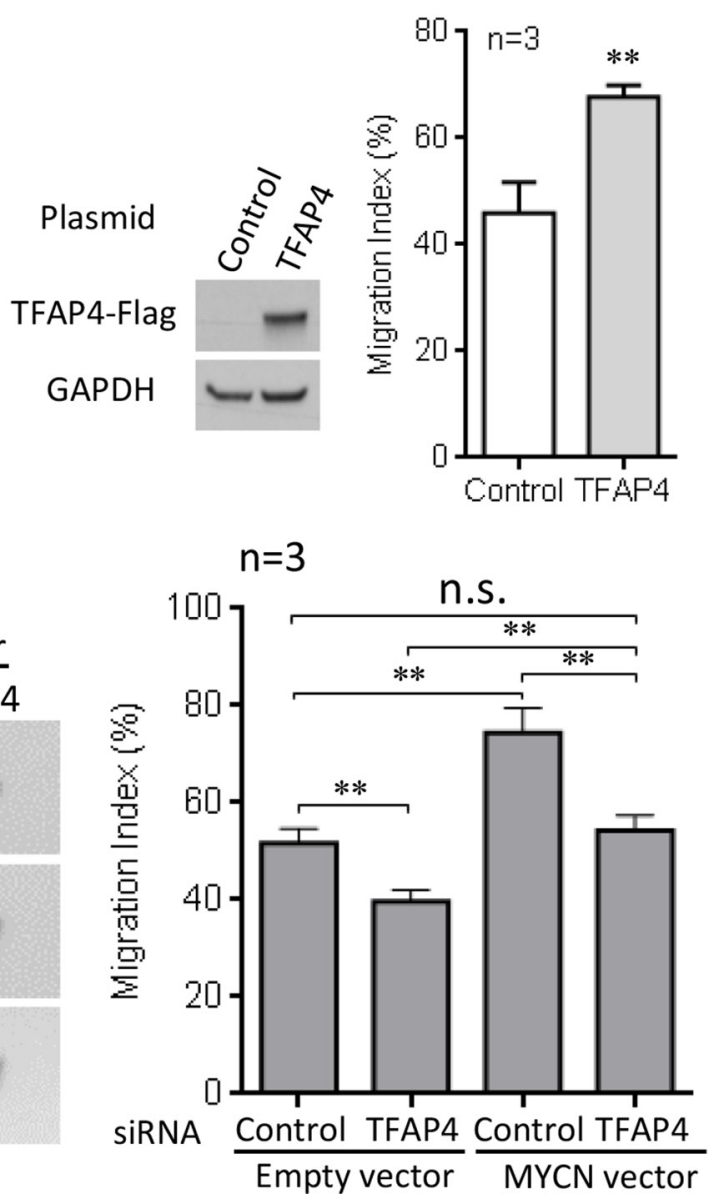

Figure 3: TFAP4 is required for neuroblastoma cell migration. Suppression of TFAP4 in BE(2)-C decreased cell motility in

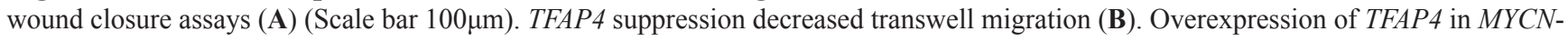
non-amplified SH-SY5Y cells increased migration $(\mathbf{C})$. Transient overexpression of MYCN in SH-SY5Y cells increased migration, and depletion of TFAP4 abrogated this effect (D). Western blots demonstrated successful transfection of MYCN plasmid, TFAP4 plasmid or TFAP4 siRNA (C, D). Mean $\pm \mathrm{SE}(n=3) . * P<0.05, * * P<0.01$. 
metastasis in certain types of human cancers other than neuroblastoma [16-18]. At the protein level, suppression of $M Y C N$ resulted in dramatic decreases in expression of SDC1 and PRPS2 in neuroblastoma BE(2)-C and SH-EP/ TET21/N cells (Figure 6A-6B). Consistently, knockdown of TFAP4 by siRNA corresponded with decreased SDC1 and PRPS2 expression (Figure 6C-6D).

Examination of the promoter regions of PRPS2 and SDC1 revealed a number of MYCN and TFAP4 binding sites in close vicinity to one another (Figure 6E), however no interaction between MYCN and TFAP4 was detected by co-immunoprecipitation (data not shown), suggesting that PRPS2 and SDC1 may be cooperatively regulated by both MYCN and TFAP4. Subsequent ChIP assays in $\mathrm{BE}(2)-\mathrm{C}$ confirmed that both MYCN and TFAP4 bound to the promoters of PRPS 2 and SDC1 in the vicinity of their respective E-box binding motifs (CACGTG for MYCN and CAGCTG for TFAP4), but not the control regions (Figure 6E). Luciferase reporter assays also showed that activity for both $P R P S 2$ and SDC1 was significantly decreased with TFAP4 or MYCN depletion, and further decreased with their combined depletion (Figure 6F). Taken together, these data indicate that both PRPS2 and $S D C 1$ are co-operatively regulated by both $\mathrm{MYCN}$ and TFAP4 in neuroblastoma cells.

\section{PRPS2 and SDC1 are effectors of MYCN- mediated neuroblastoma progression}

Knockdown of PRPS2 or SDC1 led to a marked decrease in colony forming ability of $\mathrm{BE}(2)-\mathrm{C}$ cells (Figure 7A-7B). Since SDC1 has been reported to mediate tumor growth and migration [19], we further investigated its role in the migration of $\mathrm{BE}(2)-\mathrm{C}$ cells. We observed that suppression of SDC1 significantly decreased transwell migration of these cells, while repression of PRPS 2 showed no effect on migration (Figure 7C-7D). Finally, we analyzed PRPS2 and SDC1 expression and their association with clinical outcome in the 649 neuroblastoma expression array dataset. KaplanMeier survival analysis showed that high levels of either PRPS 2 or SDC1 expression were strongly associated with poor EFS and OS (Supplementary Figure S3A-S3B), suggesting that both these genes may play important roles in MYCN-driven neuroblastoma cell proliferation and tumor progression. The prognostic significance of these two genes was also retained when the analysis was confined to the subset of $M Y C N$-amplified tumours (Supplementary Figure S3C) further suggesting a contribution to the MYCN-driven malignant phenotype. In addition, in the same dataset, we found that high levels of expression of SLC7A6, another gene positively regulated by MYCN and TFAP4, were significantly associated with poor EFS and OS, but high levels of expression of CYLD, a gene repressed by MYCN and TFAP4, were associated with good EFS and OS (Supplementary Figure S4A-S4B).

\section{The role of TFAP4 in the regulation of EMT in neuroblastoma}

TFAP4 has been shown to be a mediator of epithelial-mesenchymal transition (EMT) in colorectal cancer [7]. To investigate the role of this transcription factor in inducing an EMT phenotype in $M Y C N$-amplified neuroblastoma, we investigated a panel of eleven critical EMT-associated genes, including ACTN4, KRT8, MYH9, ROCK1, TCF3, VIM (Vimentin), ZEB1, TWIST (TWIST1), SNAIL (SNAI1), CDH1 (E-cadherin) and CDH2 ( $N$-cadherin). Initially, we referred to our gene expression profiling data on $\mathrm{BE}(2)-\mathrm{C}$ cells $30 \mathrm{~h}$ after depletion of TFAP4 with two different siRNAs to explore whether there was a significant change of expression of these genes. We found only subtle differential expression of these genes, with no single gene's expression change being greater than 1.5-fold following siRNA-mediated TFAP4 knockdown. Following this, we performed transient overexpression of TFAP4 in two neuroblastoma cell lines, SH-SY5Y and SK-N-FI which have relatively low levels of endogenous TFAP4. Overexpression of TFAP4 was confirmed by Western blot (data not shown) and RNA expression of the EMT-associated genes was measured by qPCR at 24 and 48 hours post transfection (Supplementary Figure S5). We found that $C D H 1$ was significantly upregulated by overexpression of TFAP4 at 24 and 48 hours in both SHSY5Y and SK-N-FI cell lines. SNAIL was significantly upregulated at $24 \mathrm{~h}$ in SH-SY5Y cells but not in SK-NFI cells, although a trend of increasing expression was observed in SK-N-FI cells. KRT8 and ZEB1 expression were reduced at $24 \mathrm{~h}$ in response to elevated TFAP4 levels in SH-SY5Y cells. KRT8 expression was also lower at $24 \mathrm{~h}$ in SK-N-FI cells but not statistically significant. The remaining genes displayed no significant change in the presence of overexpressed TFAP4.

\section{DISCUSSION}

In this study, we have demonstrated that TFAP4 is a direct transcriptional target of MYCN in neuroblastoma and that high levels of this transcription factor are associated with poor clinical outcome in this disease. Furthermore, TFAP4 and MYCN co-operatively regulate a defined subset of genes to drive cell proliferation and migration in MYCN-driven neuroblastoma cells.

The present study identified 15 genes with more than two-fold changes in gene expression profiling that appear to be regulated by MYCN through TFAP4 or commonly regulated by both transcription factors. Notably, TFAP4 did not regulate any genes in an antagonistic direction to MYCN in this subset of genes, suggesting that these two transcription factors cooperatively regulate specific target genes that play critical roles in the development of the aggressive phenotype of neuroblastoma. This notion was supported by the observation that MYCN and TFAP4 were 
able to bind to their respective binding sites closely located on the promoters of the two target genes, PRPS 2 and SDC1 (CD138); while simultaneous depletion of $M Y C N$ and TFAP4 resulted in further reduction of promoter activity of both these genes. PRPS2, a key rate-limiting enzyme within the nucleotide biosynthesis pathway, has been previously reported to be a MYC target gene [16]. In cancer cells, PRPS2 has been reported to be involved in nucleotide metabolism in melanoma and lymphoma and hence is proposed to be a potential therapeutic target for MYC-overexpressing cancers [16, 17]. SDC1, a transmembrane (type I) heparan sulfate proteoglycan is involved in growth factor signalling, cell proliferation, migration and cell-matrix interactions via its receptor for extracellular matrix proteins [20]. Ishikawa et al, (2010) reported that suppression of SDC1 leads to more invasive and metastatic tumor cells [21]. The molecule can exist in either a membrane-bound or soluble form, and the

\section{A Oberthuer cohort}
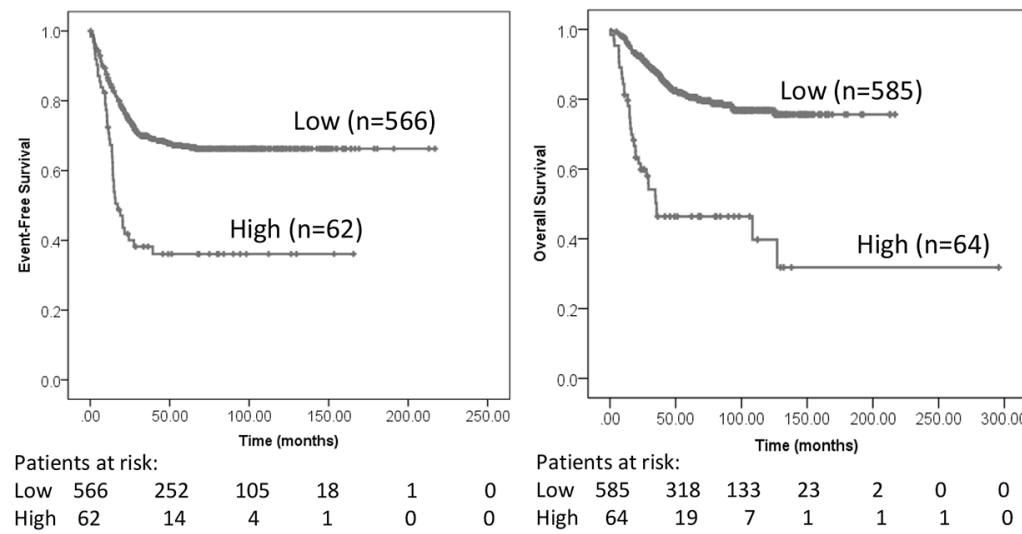

B COG cohort
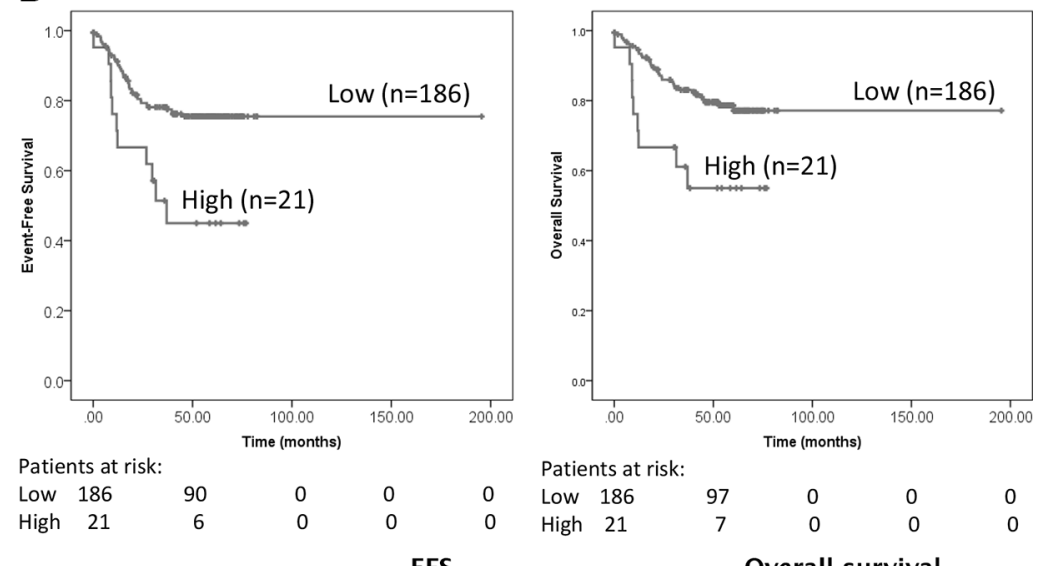

Patients at risk:

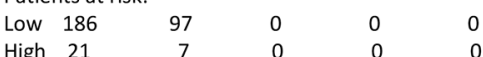

\begin{tabular}{lcccccc} 
& \multicolumn{2}{c}{ EFS } & & \multicolumn{2}{c}{ Overall survival } \\
\cline { 2 - 3 } \cline { 5 - 6 } & HR $(95 \% \mathrm{CI})$ & $\boldsymbol{P}$ & & HR $(95 \% \mathrm{CI})$ & $\boldsymbol{P}$ \\
\hline Oberthuer cohort & $2.6(1.8-3.7)$ & $<0.001$ & & $4.1(2.8-6.1)$ & $<0.001$ \\
COG cohort & $2.7(1.4-5.2)$ & 0.003 & & $2.6(1.3-5.5)$ & 0.007 \\
\hline
\end{tabular}

\section{Oberthuer cohort}

COG cohort
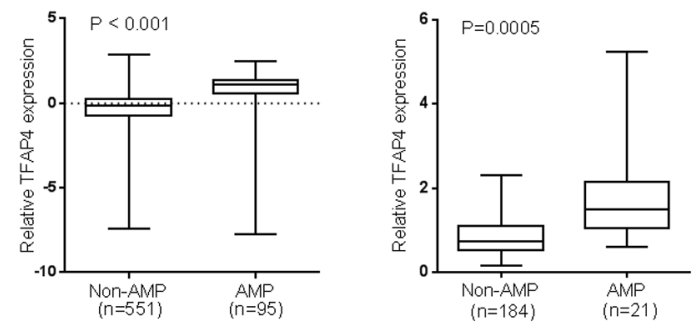

Figure 4: TFAP4 gene expression is prognostic for poor outcome in primary neuroblastoma. Kaplan-Meier curves for event-free survival (EFS) and overall survival (OS) from (A) Oberthuer cohort $(n=649)$ and (B) COG cohort $(n=208)$, dichotomized around the upper decile. (C) TFAP4 expression levels were significantly higher in $M Y C N$-amplified compared to non-MYCN-amplified tumors. 
former cell-surface SDC1 has been shown to have roles in tumor formation and progression [22], while shed SDC1 correlates with a more aggressive phenotype and may be a potential prognostic marker for a number of adult cancers including colorectal cancer, lung cancer and multiple myeloma [18].

SLC7A6, the only other gene found to be positively regulated by both $\mathrm{MYCN}$ and TFAP4, is a sodium dependent neutral amino acid transporter belonging to the L-type amino acid transporter (LAT) family, and increased expression of some LAT family members has been shown to be critical for control of protein translation in cancer via the mTORC1 pathway [23]. Our findings that high levels of expression of PRPS2, SDC1 and also SLC7A6 are associated with poor clinical outcome in neuroblastoma, and that PRPS2 and SDC1 are important in proliferation, suggest that these genes may facilitate tumor progression in MYC- and MYCN-driven cancers.

TFAP4 has been shown to repress or activate different target genes, and it is not able to form heterodimers with other helix-loop-helix transcription factors [5]. In our study, we found that TFAP4 was involved more often in repression $(9.45 \%)$ than activation $(3.06 \%)$ of MYCN target genes. Similarly, ChIPsequencing analysis in colorectal cancer cells showed that ChIP signals from TFAP4-repressed genes were more pronounced than those of TFAP4-activated genes [7]. These data suggest that TFAP4 has a major role in gene repression in tumors with deregulated MYC. One of the nine genes we confirmed to be repressed by both MYCN and TFAP4, CYLD, a deubiquitinating enzyme that negatively regulates $N F-\kappa B$ activation [24], is a well-established tumor suppressor gene, and loss of $C Y L D$ expression has been observed in various human cancer types [25]. Our findings that high CYLD levels are predictive for good prognosis in neuroblastoma (Supplementary Figure S4) are in agreement with a recent report showing that higher $C Y L D$ expression in neuroblastoma patient samples correlated with better survival and early tumor stages, and CYLD expression was significantly lower in $M Y C N$-amplified tumors [26]. In addition to $C Y L D$, knockdown of DENND5A in MDCKII cells was reported to lead to an increase in cell migration [27], while SSU72 was shown to be downregulated in the progression to hormone-refractory prostate cancer [28]. In gastric cancer cells, COPS 8 has been reported to be part of $\mathrm{G}$ protein-coupled receptor pathway responsible for inhibiting the activation of $\mathrm{NF}-\kappa \mathrm{B}$ [29]. In contrast to these results however, overexpression of $F M R 1$, which encodes fragile $\mathrm{X}$ mental retardation protein, has been associated with aggressiveness of breast cancer while its inhibition led to a reduction in invasiveness [30]. Interestingly, some of the highest levels of FMR1 are found in differentiated neurons and Gessert et al, [31] have shown that this RNA binding protein is necessary for proper neural crest development (the cell of origin of neuroblastoma) in Xenopus laevis. Thus, it remains to be established what role FMR1 has in neuroblastoma tumorigenesis. The remaining genes found to be negatively regulated by MYCN and TFAP4, appear to be largely uncharacterised in cancer and their functions in neuroblastoma require investigation.

In colorectal cancer, TFAP4 was found to be required for $\mathrm{MYC}$-induced EMT, migration, and invasion providing strong evidence for this transcription factor being a new regulator of EMT contributing directly to colorectal cancer metastasis [7]. Although MYC can bind to the promoter of $S N A I L$, a transcription factor known to induce EMT [32], induction of SNAIL by MYC is largely mediated via upregulation of TFAP4 [7]. In addition, these authors found that SNAIL is also a target of TFAP4. Interestingly, in melanoma cells, SNAIL has been shown to inhibit expression of CYLD, which in turn leads to increased melanoma proliferation and invasion [33].
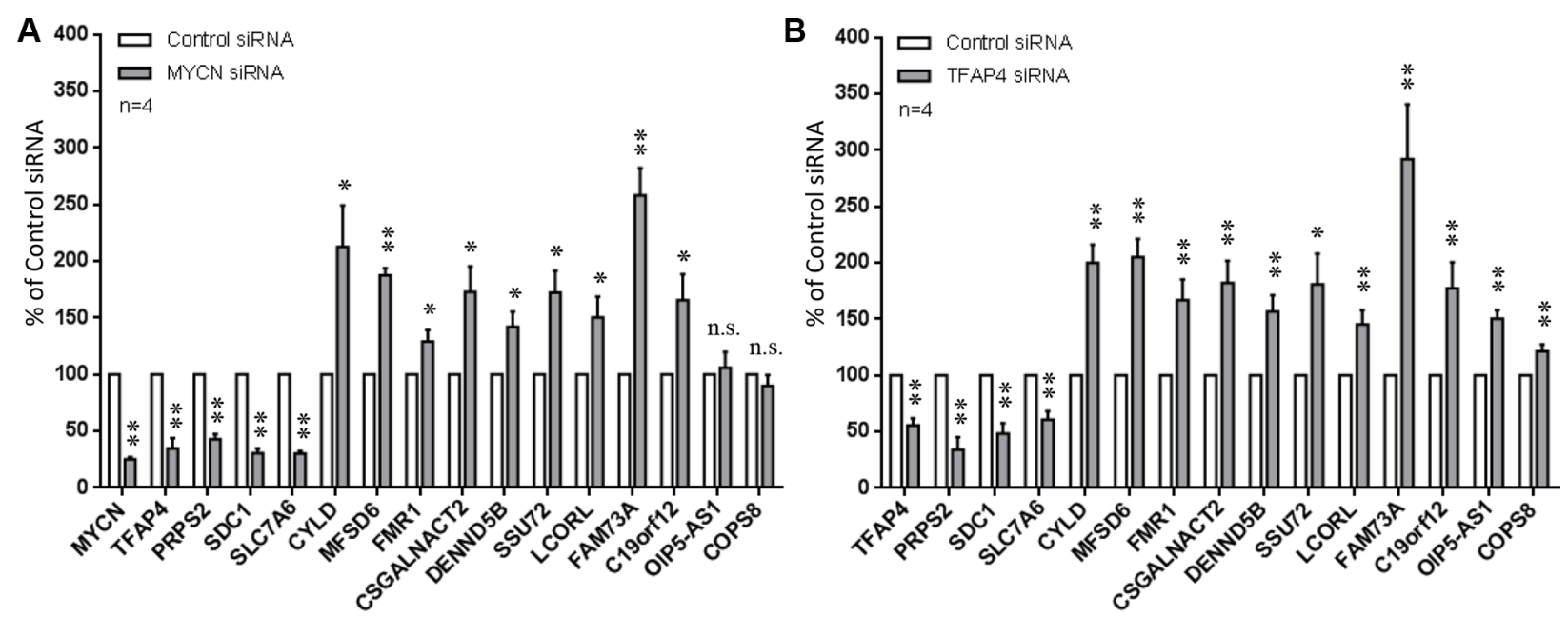

Figure 5: Confirmation of differentially expressed genes from microarray. Gene expression was measured by qPCR $48 \mathrm{~h}$ after depletion of MYCN (A) or TFAP4 (B) in BE(2)-C cells. Mean \pm S.E. (four independent transfections with two siRNAs to either MYCN or TFAP4). $* P<0.05, * * P<0.01$. 
Taken together with our study, TFAP4 appears to be initially upregulated by MYC or MYCN, after which it cooperatively regulates the same target genes to maximize rapid transcriptional activity in cancer cells. In this regard, a genome-wide analysis of TFAP4 DNA binding using ChIP-sequencing revealed a similar overall gene distribution pattern for TFAP4- and MYC-binding sites in colorectal cancer [7], suggesting that TFAP4 could be involved in regulation of a large number of genes targeted by MYC in this malignancy, and further supporting the concept of TFAP4 and MYC cooperatively regulating a number of genes in MYC-driven cancers.

A

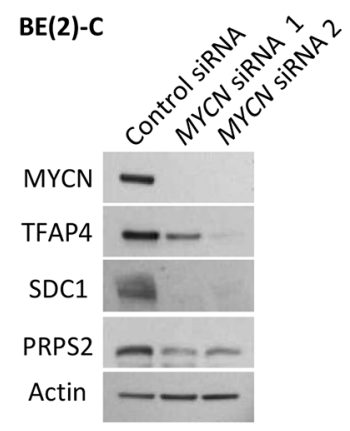

B

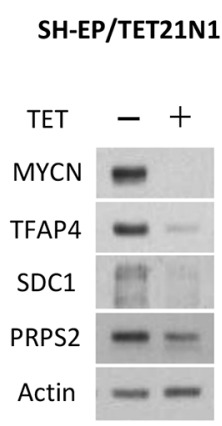

C

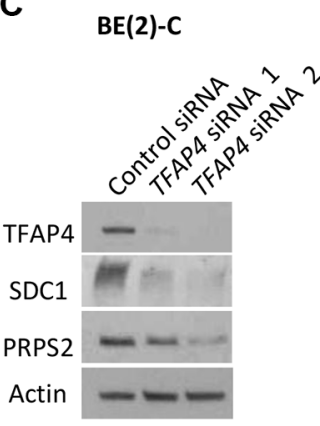

D

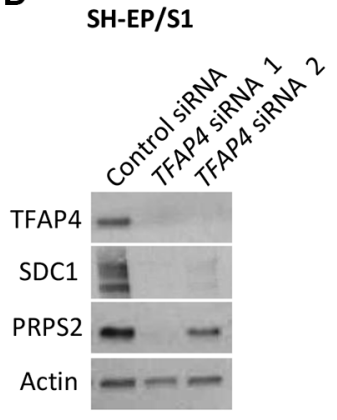

In MYC-induced EMT in colorectal cancer, TFAP4 has been shown to regulate a number of EMT-associated genes such as CDH1,CDH2, VIM and SNAIL. TFAP4 transcriptionally induces $S N A I L$, and both TFAP4 and SNAIL repress $C D H 1$. In addition, TFAP4 protein is associated with Vimentin expression and inversely correlated with E-cadherin expression in seven colorectal cancer cell lines [7]. Consistent with this study, we found upregulation of SNAIL as well as downregulation of KRT8 by elevated expression of TFAP4 in SH-SY5Y cells (Supplementary Figure S5). However, CDH1 was also upregulated in SH-SY5Y cells as well as in
F
E

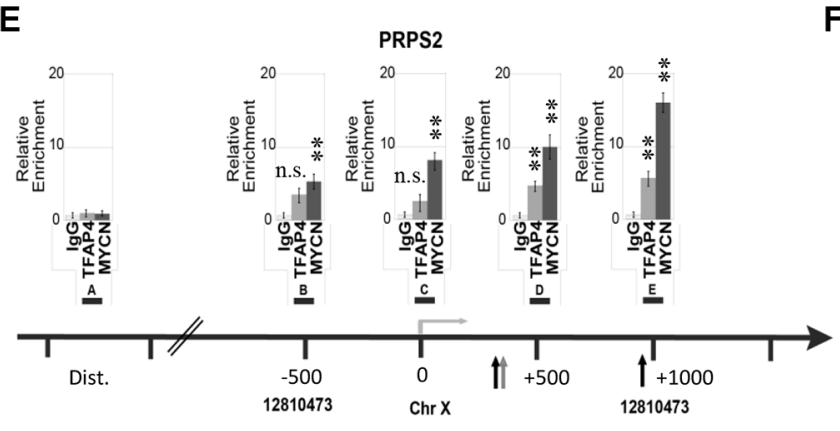

PRPS2

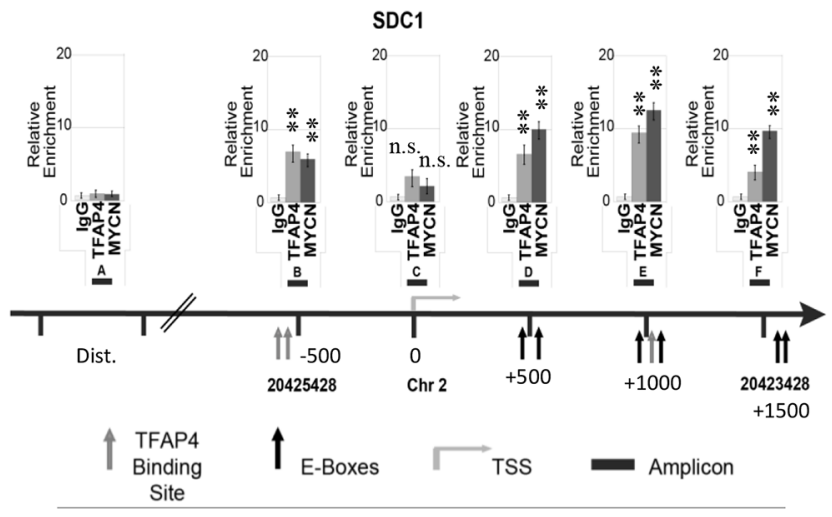

24h

Control siRNA

TFAP4 SIRNA MYCN SIRNA

TFAP4 + MYCN SDC1

Control siRNA TFAP4 SIRNA TFAP4 + MYCN SIRNA
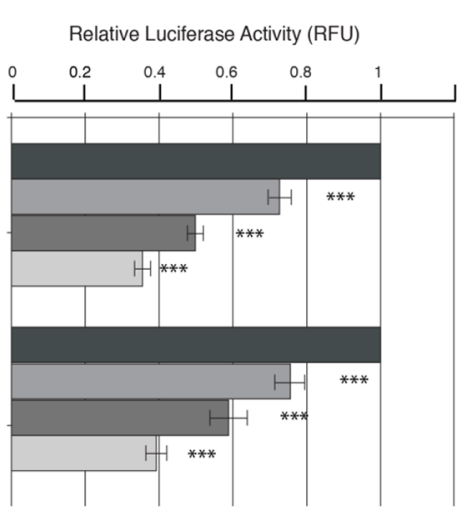

$48 \mathrm{~h}$

PRPS2

Control siRNA TFAP4 SIRNA MYCN SIRNA TFAP4 + MYCN SiRNA

SDC1

Control siRNA MYCN SIRNA TFAP4 + MYCN SiRNA
Relative Luciferase Activity (RFU)

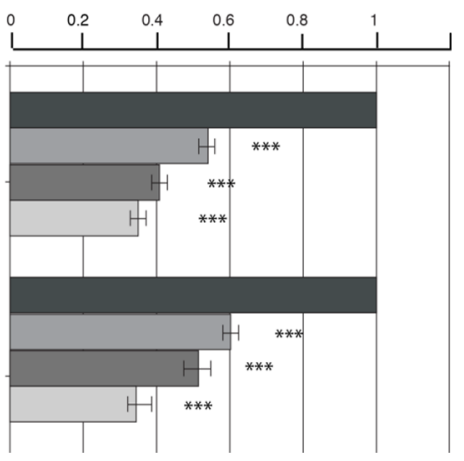

Figure 6: PRPS2 and SDC1 are direct transcriptional targets of MYCN and TFAP4 in neuroblastoma. (A-D) Western blots of PRPS2 and SDC1 expression in BE(2)-C and SH-EP/S1 $48 \mathrm{~h}$ after suppression of MYCN or TFAP4 or $72 \mathrm{~h}$ after suppression of MYCN expression in SH-EP/TET21/N cells $(n \geq 2)$. (E) Quantitative ChIP assays on BE(2)-C cells. Fold enrichment is relative to the preimmune serum. Mean \pm S.E. $(n=5)$ in which each region was amplified by qPCR in triplicate. Bent arrow: transcriptional start site (TSS); Dist. (Distal region); grey arrow: TFAP4 binding site; black arrow: E-box (MYCN binding site); black boxes: amplicons indicated with a capital letter. The chromosome and coordinates $(\mathrm{bp})$ are provided. (F) Luciferase activity was determined following transfection of reporter constructs into BE(2)-C transfected with TFAP4 and/or MYCN siRNA, or control siRNA. ***P<0.001. 
SK-N-FI cells, which is not in agreement with the general finding that $\mathrm{CDH} 1$ is repressed in EMT. As an early event in EMT, cells commonly undergo a switch from E-cadherin to N-cadherin, and N-cadherin expression has been associated with increased motility and invasiveness [34]. In our study, $C D H 2$ remained unchanged following overexpression of TFAP4. In addition, we observed no change in expression of TWIST, a well-established EMT-inducing gene that promotes tumor invasion and metastasis [35]. Furthermore, we saw reduced expression of $Z E B 1$, another master EMT-inducing gene, which is generally activated in EMT [36]. Importantly, we found no change in gene expression of Vimentin, a hallmark in cells undergoing EMT (high Vimentin and low E-cadherin expression) [37]. A number of other genes involved in EMT in neuroblastoma, such as ACTN4, MYH9, ROCK1 and TCF3 [38, 39], failed to show any significant changes in our studies. Finally, we did not observe obvious cell morphological changes 72 hours after transient overexpression of TFAP4.

Collectively, the present data do not suggest TFAP4 has a major role in the EMT phenotype of neuroblastoma. We showed TFAP4 promotes cell migration in

\section{A Control siRNA PRPS2 siRNA 1 PRPS2 siRNA 2}

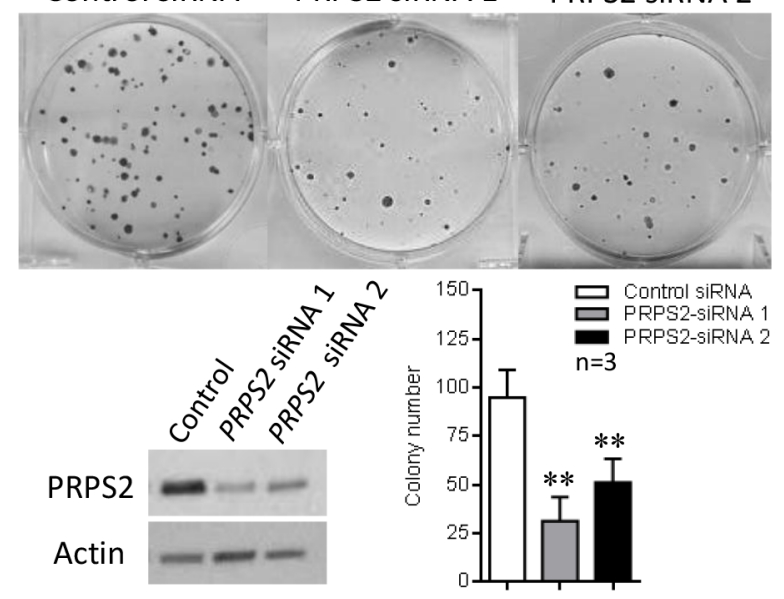

C

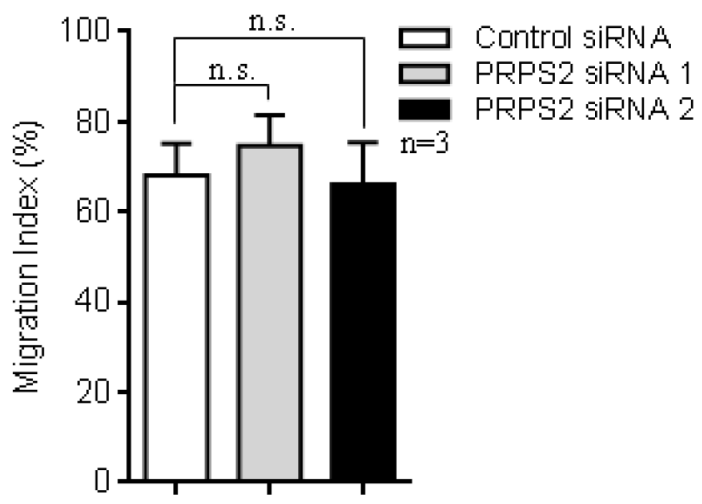

neuroblastoma cell lines BE(2)-C, SH-SY5Y and SK-N-FI (Figure 3, Supplementary Figure S2A) and we believe this is, at least partly, achieved through activation of TFAP4 target genes such as SDC1. However, since transient expression of TFAP4 caused upregulation of SNAIL and downregulation of KRT8 in SH-SY5Y cells, and a trend in reduction of $C D H 1$ at 48 hours compared to 24 hours (still higher than control) in both SH-SY5Y and SK-NFI cells (Supplementary Figure S5), it could be possible that the effect of TFAP4 on EMT happens at much later timepoints, and this remains to be explored.

MYC is a "master regulator" of two interrelated processes in transformed cells, cellular growth and metabolism, and remodelling of cancer metabolic pathways by MYC is vital for maintenance of a rapid cellular proliferation phenotype in MYC-transformed cells $[40,41]$. To our knowledge, this is the first study to investigate the role of TFAP4 in MYCN-driven neuroblastoma. Our data support the existence of a regulatory circuit between MYCN and TFAP4, where TFAP4 is directly induced by MYCN, then cooperates with MYCN to regulate a subset of MYCN-target genes involved in cancer cell proliferation and metastasis,
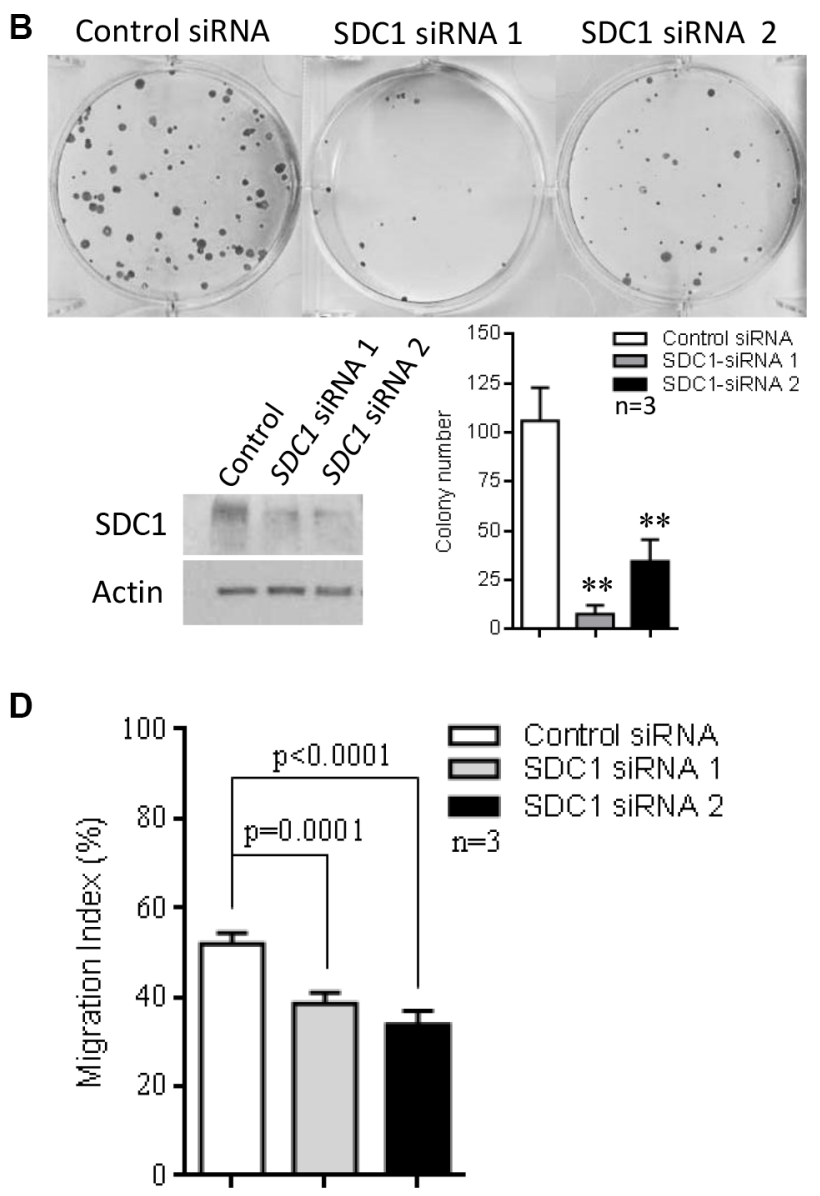

Figure 7: The role of PRPS2 and SDC1 in neuroblastoma progression. (A-B) Suppression of $P R P S 2$ or $S D C 1$ resulted in reduction of colony forming ability in $\mathrm{BE}(2)-\mathrm{C}$ cells. (C-D) SDC1 suppression significantly decreased migration, while PRPS2 suppression showed no significant effect. Mean $\pm \mathrm{SD}(n=3),{ }^{*} * P<0.01$. 
nucleotide and protein synthesis and growth. In particular, we have identified PRPS 2 and SDC1 as genes that are positively regulated by both MYCN and TFAP4, and which represent novel candidate therapeutic targets for MYCN-driven neuroblastoma.

\section{MATERIALS AND METHODS}

\section{Gene silencing, transfection, cellular assays}

Human neuroblastoma cell lines BE(2)-C and SH-EP were obtained from the laboratory of Barbara Spengler [42]. Human SH-EP/TET21/N cells, derived from SH-EP neuroblastoma cells, express MYCN under the control of tetracycline (Tet-off) [43, 44]. SH-EP/S1 cells were derived from SH-EP cells by stable transfection with $M Y C N$-expression vector. Neuroblastoma cell lines IMR32, SH-SY5Y, SK-N-FI and CHP-134 were obtained from American Type Culture Collection (Rockville, MD). Cell lines were systematically validated using short tandem repeat genetic profiling (CellBank Australia, Sydney) and mycoplasma tested. Cell lines were cultured in DMEM or RPMI containing 10\% fetal calf serum (FCS).

Lipofectamine $^{\circledR}$ RNAiMAX and Lipofectamine 2000 (Invitrogen) were used to deliver siRNA (20-40 nM) or plasmids (5 $\mu \mathrm{g} A P 4-F L A G$ (OriGene, MD), MYCN (\#240081, Agilent Technologies) or empty vector). Qiagen siRNAs were: Control (\#SI03650318); MYCN (\#SI03078222,\#SI03087518); TFAP4 (\#SI00049322, \#SI03057558); SDC1 (\#SI00020601, \#SI03072230), PRPS2 (\#SI00042903, \#SI03076997). SMARTpool human MYCN siRNA was from Dharmacon (\#M-003913-01).

Colony forming assays were performed as described [45], with cells replated $48 \mathrm{~h}$ post-transfection and colonies of greater than 50 cells counted. For cell cycle analysis, cells at $48 \mathrm{~h}$ or $72 \mathrm{~h}$ post-transfection were fixed with ice-cold $70 \%$ ethanol for $1 \mathrm{~h}$ before incubation at $37^{\circ} \mathrm{C}$ (30 min) in PBS with added propidium iodide $(50 \mu \mathrm{g} / \mathrm{mL})$ and RNase A ( $2 \mu \mathrm{g} / \mathrm{mL})$. Stained cells were analyzed for DNA content on a FACSCalibur flow cytometer using CELLQuest analysis software (BD Biosciences).

Wound closure assays and transwell migration assays were performed as published [46, 47].

\section{Western blot}

Western blots were performed according to standard procedures [48] using $25 \mu \mathrm{g}$ of whole-cell extract. Syndecan-1 (SDC1) protein samples were prepared by scraping cells in lysis buffer. Antibodies used were MYCN (B8.4B, \#sc-53993, 1:2000, or C-19, \#sc-791, 1:500, Santa Cruz) [49], p27 kip1 (BD Biosciences \#610241, 1:2000) [50], TFAP4 (Abcam \#ab58288, 1:2000), FLAG (anti-Flag-M2, Agilent Technologies \#200471, 1:2000), SDC1 (D4Y7H, Cell Signaling \#12922S, 1:1000), PRPS2
(Abnova \#H00005634-A01, 1:1000) [16], GAPDH (G9, Santa Cruz \#sc-365062, 1:3000), Actin (Sigma-Aldrich \#A2066, 1:5000).

\section{Microarray analysis}

Neuroblastoma BE(2)-C cells were transfected with scrambled control siRNA or two independent siRNAs for MYCN and TFAP4. $30 \mathrm{~h}$ post-transfection, total RNA was extracted with RNeasy Plus Mini kit (Qiagen). Differential gene expression was examined with GeneChip ${ }^{\circledR}$ Human Genome U133 Plus 2.0 Array (Affymetrix). Results were loaded into $\mathrm{R}$ package and analysed with BioConductor software.

\section{Real-time quantitative PCR and Taqman Low Density Array (TLDA) analyses}

RNA was extracted using an RNA Extraction kit (Qiagen) and reverse transcribed with MMLV reverse transcriptase (Life Technologies). Gene expression was determined by quantitative PCR (qPCR) using the ABI7900HT sequence detection systems (Applied Biosystems, ThermoFisher Scientific) for $\operatorname{TaqMan}^{\circledR}$ Assays, or CFX96 real-time PCR detection system (BioRad) for SYBR ${ }^{\circledR}$ Green assays. The $\Delta \Delta C$ t method was used to compare expression of target genes normalized to the expression of reference genes (GUSB, HPRT or actin).

Gene expression analyses were performed on 208 primary neuroblastoma tumors (COG cohort) from patients enrolled in Children's Oncology Group (COG) Neuroblastoma Biology Study 9047 [46]. qPCR with TaqMan $^{\circledR}$ gene expression assays were conducted on a TLDA platform using a 7900HT Fast Real-Time PCR system (Applied Biosystems, ThermoFisher Scientific). TLDA cards were loaded with $125 \mathrm{ng}$ cDNA (RNA equivalent) per loading port. Gene expression levels were determined using the $\Delta \Delta \mathrm{Ct}$ method relative to a calibrator [48]. Expression values were calculated as the geometric mean of values normalized to control genes HPRT, GUSB and PPIA.

TaqMan $^{\circledR}$ Assays for qPCR were: TFAP4 (Hs00231478_m1), MYCN (Hs00232074_m1); SDC1 (Hs00896423_m1); PRPS2 (Hs00267624_m1); SLC7A6 (Hs00938056_m1); CYLD (Hs00211000_m1); MFSD6 (Hs0021446⿸厂二__m1); FMR1 (Hs00924547 $\mathrm{m1}$ ); C SGALNACT2 (Hs00603821_m1); DENND5B (Hs00958915_m1); SSU72 (Hs00982637_m1); LCORL (Hs00766084_m1); FAM73A (Hs01594834_m1), C19orf12 (Hs01107514_m1); OIP5-AS1 (Hs01587688_g1); COPS8 (Hs00991301_g1); HPRT (Hs02800695_m1); GUSB (Hs00939627_m1); PPIA (Hs99999904_m1). qPCR assays for TFAP4 expression using SYBR ${ }^{\circledR}$ Green were performed using published primers [6]. qPCR assays for EMTassociated genes using SYBR ${ }^{\circledR}$ Green were performed using primers listed in Supplementary Table S2. 


\section{Chromatin immunoprecipitation (ChIP) and luciferase assays}

ChIP assays were performed as described [43] on neuroblastoma BE(2)-C and SH-EP/TET21/N cells. Antibodies employed for ChIP assays were: MYCN (\#sc-53993, Santa Cruz Biotechnology) [49], MAX (\#sc-197, Santa Cruz) [51] and TFAP4 (\#HPA001912, Sigma-Aldrich) [7]. Primers for quantitative ChIP are listed in Supplementary Table S1. Luciferase assays were performed as published [43].

\section{Statistical analysis}

For molecular and cellular assays, differences between two groups were analyzed by two-tailed Student's $t$-test. $P<0.05$ was considered statistically significant. Associations between expression levels of a given gene and clinical characteristics of patients were analyzed using Fisher's exact test. Univariate and multivariate analyses for event-free survival (EFS) and overall survival (OS) were performed using SPSS version 22 (IBM, Mainz, Germany) as described [46]. For each cutoff point, a Cox model produced a $P$-value and hazard ratio and the optimal expression cutoff point was determined as described previously [52]. Pearson correlation test was performed to analyze the correlation between expression of TFAP4 and MYCN.

\section{Abbreviations}

ChIP, chromatin immunoprecipitation; COG, Children's Oncology Group; CYLD, cylindromatosis; EFS, event-free survival; EMT, epithelial-mesenchymal transition; OS, overall survival; PRPS2, phosphoribosylpyrophosphate synthetase 2; SDC1, syndecan-1; TFAP4, transcription factor activating enhancer binding protein-4.

\section{CONFLICTS OF INTEREST}

The authors disclose no potential conflicts of interest.

\section{GRANT SUPPORT}

This work was supported by grants from the National Health and Medical Research Council [GM, MH, MN], Cancer Institute New South Wales [GM, MH, $\mathrm{MN}]$ and Italian Association for Research on Cancer, AIRC-IG11400 [GP]. JK is supported by an Australian Postgraduate Award. TL is supported by an Australian Research Council Future Fellowship.

\section{REFERENCES}

1. Malynn BA, de Alboran IM, O’Hagan RC, Bronson R, Davidson L, DePinho RA, Alt FW. N-myc can functionally replace c-myc in murine development, cellular growth, and differentiation. Genes Dev. 2000; 14: 1390-1399.

2. Prochownik EV, Vogt PK. Therapeutic Targeting of Myc. Genes Cancer. 2010; 1: 650-659. doi: 10.1177/1947601910377494.

3. Dang CV. MYC on the path to cancer. Cell. 2012; 149: $22-35$.

4. Maris JM. Recent Advances in Neuroblastoma. N Engl J Med. 2010; 362: 2202-2211.

5. Hu YF, Luscher B, Admon A, Mermod N, Tjian R. Transcription factor AP-4 contains multiple dimerization domains that regulate dimer specificity. Genes Dev. 1990; 4: 1741-1752.

6. Jung P, Menssen A, Mayr D, Hermeking H. AP4 encodes a c-MYC-inducible repressor of p21. Proc Natl Acad Sci U S A. 2008; 105: 15046-15051.

7. Jackstadt R, Roh S, Neumann J, Jung P, Hoffmann R, Horst D, Berens C, Bornkamm GW, Kirchner T, Menssen A, Hermeking H. AP4 is a mediator of epithelial-mesenchymal transition and metastasis in colorectal cancer. J Exp Med. 2013; 210: 1331-1350.

8. Cao J, Tang M, Li WL, Xie J, Du H, Tang WB, Wang H, Chen XW, Xiao H, Li Y. Upregulation of activator protein-4 in human colorectal cancer with metastasis. Int J Surg Pathol. 2009; 17: 16-21.

9. Liu X, Zhang B, Guo Y, Liang Q, Wu C, Wu L, Tao K, Wang G, Chen J. Down-regulation of AP-4 inhibits proliferation, induces cell cycle arrest and promotes apoptosis in human gastric cancer cells. PLoS One. 2012; 7: e37096.

10. Gong H, Han S, Yao H, Zhao H, Wang Y. AP4 predicts poor prognosis in nonsmall cell lung cancer. Mol Med Rep. 2014; 10: 336-340.

11. Kocak H, Ackermann S, Hero B, Kahlert Y, Oberthuer A, Juraeva D, Roels F, Theissen J, Westermann F, Deubzer H, Ehemann V, Brors B, Odenthal M, et al. Hox-C9 activates the intrinsic pathway of apoptosis and is associated with spontaneous regression in neuroblastoma. Cell Death Dis. 2013; 4: e586.

12. Huang M, Weiss WA. Neuroblastoma and MYCN. Cold Spring Harb Perspect Med. 2013; 3: a014415.

13. Tee AE, Ling D, Nelson C, Atmadibrata B, Dinger ME, Xu N, Mizukami T, Liu PY, Liu B, Cheung B, Pasquier E, Haber M, Norris MD, et al. The histone demethylase JMJD1A induces cell migration and invasion by up-regulating the expression of the long noncoding RNA MALAT1. Oncotarget. 2014; 5: 1793-1804. doi: 10.18632/oncotarget.1785. 
14. Herkert B, Eilers M. Transcriptional repression: the dark side of myc. Genes Cancer. 2010; 1: 580-586. doi: 10.1177/1947601910379012.

15. Gherardi S, Valli E, Erriquez D, Perini G. MYCN-mediated transcriptional repression in neuroblastoma: the other side of the coin. Front Oncol. 2013; 3: 42.

16. Mannava S, Grachtchouk V, Wheeler LJ, Im M, Zhuang D, Slavina EG, Mathews CK, Shewach DS, Nikiforov MA. Direct role of nucleotide metabolism in C-MYC-dependent proliferation of melanoma cells. Cell Cycle. 2008; 7: 2392-2400.

17. Cunningham JT, Moreno MV, Lodi A, Ronen SM, Ruggero D. Protein and nucleotide biosynthesis are coupled by a single rate-limiting enzyme, PRPS2, to drive cancer. Cell. 2014; 157: 1088-1103.

18. Gharbaran R. Advances in the molecular functions of syndecan-1 (SDC1/CD138) in the pathogenesis of malignancies. Crit Rev Oncol Hematol. 2015; 94: 1-17.

19. Yang Y, Yaccoby S, Liu W, Langford JK, Pumphrey CY, Theus A, Epstein J, Sanderson RD. Soluble syndecan-1 promotes growth of myeloma tumors in vivo. Blood. 2002; 100: 610-617.

20. Ramani VC, Purushothaman A, Stewart MD, Thompson CA, Vlodavsky I, Au JL, Sanderson RD. The heparanase/syndecan-1 axis in cancer: mechanisms and therapies. FEBS J. 2013; 280: 2294-2306.

21. Ishikawa $\mathrm{T}$, Kramer RH. Sdc1 negatively modulates carcinoma cell motility and invasion. Exp Cell Res. 2010; 316: 951-965.

22. Szatmari T, Dobra K. The role of syndecan-1 in cellular signaling and its effects on heparan sulfate biosynthesis in mesenchymal tumors. Front Oncol. 2013; 3: 310.

23. Wang Q, Holst J. L-type amino acid transport and cancer: targeting the mTORC1 pathway to inhibit neoplasia. Am J Cancer Res. 2015; 5: 1281-1294.

24. Brummelkamp TR, Nijman SM, Dirac AM, Bernards R. Loss of the cylindromatosis tumour suppressor inhibits apoptosis by activating NF-kappaB. Nature. 2003; 424: 797-801.

25. Sun SC. CYLD: a tumor suppressor deubiquitinase regulating NF-kappaB activation and diverse biological processes. Cell Death Differ. 2010; 17: 25-34.

26. Kobayashi T, Masoumi KC, Massoumi R. Deubiquitinating activity of CYLD is impaired by SUMOylation in neuroblastoma cells. Oncogene. 2014; 34: 2251-2260.

27. Li Y, Xu J, Xiong H, Ma Z, Wang Z, Kipreos ET, Dalton S, Zhao S. Cancer driver candidate genes AVL9, DENND5A and NUPL1 contribute to MDCK cystogenesis. Oncoscience. 2014; 1: 854-865. doi: 10.18632/oncoscience.107.

28. Tamura K, Furihata M, Tsunoda T, Ashida S, Takata R, Obara W, Yoshioka H, Daigo Y, Nasu Y, Kumon H, Konaka H, Namiki M, Tozawa K, et al. Molecular features of hormone-refractory prostate cancer cells by genome-wide gene expression profiles. Cancer Res. 2007; 67: 5117-5125.
29. Crone SG, Jacobsen A, Federspiel B, Bardram L, Krogh A, Lund AH, Friis-Hansen L. microRNA-146a inhibits G protein-coupled receptor-mediated activation of NF-kappaB by targeting CARD10 and COPS8 in gastric cancer. Mol Cancer. 2012; 11: 71.

30. Luca R, Averna M, Zalfa F, Vecchi M, Bianchi F, La Fata G, Del Nonno F, Nardacci R, Bianchi M, Nuciforo P, Munck S, Parrella P, Moura R, et al. The fragile X protein binds mRNAs involved in cancer progression and modulates metastasis formation. EMBO Mol Med. 2013; 5: 1523-1536.

31. Gessert S, Bugner V, Tecza A, Pinker M, Kuhl M. FMR1/ FXR1 and the miRNA pathway are required for eye and neural crest development. Dev Biol. 2010; 341: 222-235.

32. Smith AP, Verrecchia A, Faga G, Doni M, Perna D, Martinato F, Guccione E, Amati B. A positive role for Myc in TGFbeta-induced Snail transcription and epithelial-tomesenchymal transition. Oncogene. 2009; 28: 422-430.

33. Massoumi R, Kuphal S, Hellerbrand C, Haas B, Wild P, Spruss T, Pfeifer A, Fassler R, Bosserhoff AK. Downregulation of CYLD expression by Snail promotes tumor progression in malignant melanoma. J Exp Med. 2009; 206: 221-232.

34. Araki K, Shimura T, Suzuki H, Tsutsumi S, Wada W, Yajima T, Kobayahi T, Kubo N, Kuwano H. E/N-cadherin switch mediates cancer progression via TGF-beta-induced epithelial-to-mesenchymal transition in extrahepatic cholangiocarcinoma. Br J Cancer. 2011; 105: 1885-1893.

35. Kang Y, Massague J. Epithelial-mesenchymal transitions: twist in development and metastasis. Cell. 2004; 118: 277-279.

36. Lamouille S, Xu J, Derynck R. Molecular mechanisms of epithelial-mesenchymal transition. Nat Rev Mol Cell Biol. 2014; 15: 178-196.

37. Lee JM, Dedhar S, Kalluri R, Thompson EW. The epithelialmesenchymal transition: new insights in signaling, development, and disease. J Cell Biol. 2006; 172: 973-981.

38. Piskareva O, Harvey H, Nolan J, Conlon R, Alcock L, Buckley P, Dowling P, Henry M, O’Sullivan F, Bray I, Stallings RL. The development of cisplatin resistance in neuroblastoma is accompanied by epithelial to mesenchymal transition in vitro. Cancer Lett. 2015; 364: $142-155$.

39. Nozato M, Kaneko S, Nakagawara A, Komuro $H$. Epithelial-mesenchymal transition-related gene expression as a new prognostic marker for neuroblastoma. Int J Oncol. 2013; 42: 134-140.

40. Miller DM, Thomas SD, Islam A, Muench D, Sedoris K. c-Myc and cancer metabolism. Clin Cancer Res. 2012; 18: 5546-5553.

41. Dang CV. MYC, metabolism, cell growth, and tumorigenesis. Cold Spring Harb Perspect Med. 2013; 3: a014217.

42. Spengler BA, Ross RA, Biedler JL. Differential drug sensitivity of human neuroblastoma cells. Cancer Treat Rep. 1986; 70: 959-965. 
43. Porro A, Haber M, Diolaiti D, Iraci N, Henderson M, Gherardi S, Valli E, Munoz MA, Xue C, Flemming C, Schwab M, Wong JH, Marshall GM, et al. Direct and coordinate regulation of ATP-binding cassette $(\mathrm{ABC})$ transporter genes by MYC factors generates specific transcription signatures which significantly affect the chemoresistance phenotype of cancer cells. J Biol Chem. 2010; 285: 19532-19543.

44. Lutz W, Stohr M, Schurmann J, Wenzel A, Lohr A, Schwab M. Conditional expression of N-myc in human neuroblastoma cells increases expression of alphaprothymosin and ornithine decarboxylase and accelerates progression into S-phase early after mitogenic stimulation of quiescent cells. Oncogene. 1996; 13: 803-812.

45. Xue C, Haber M, Flemming C, Marshall GM, Lock RB, MacKenzie KL, Gurova KV, Norris MD, Gudkov AV. p53 determines multidrug sensitivity of childhood neuroblastoma. Cancer Res. 2007; 67: 10351-10360.

46. Henderson MJ, Haber M, Porro A, Munoz MA, Iraci N, Xue C, Murray J, Flemming CL, Smith J, Fletcher JI, Gherardi S, Kwek C, Russell AJ, et al. ABCC multidrug transporters in childhood neuroblastoma: clinical and biological effects independent of cytotoxic drug efflux. J Natl Cancer Inst. 2011; 103: 1236-1251.

47. Byrne FL, Yang L, Phillips PA, Hansford LM, Fletcher JI, Ormandy CJ, McCarroll JA, Kavallaris M. RNAi-mediated stathmin suppression reduces lung metastasis in an orthotopic neuroblastoma mouse model. Oncogene. 2013; 33: 882-890.
48. Haber M, Smith J, Bordow SB, Flemming C, Cohn SL, London WB, Marshall GM, Norris MD. Association of High-Level MRP1 Expression With Poor Clinical Outcome in a Large Prospective Study of Primary Neuroblastoma. J Clin Oncol. 2006; 24: 1546-1553.

49. Westermann F, Muth D, Benner A, Bauer T, Henrich KO, Oberthuer A, Brors B, Beissbarth T, Vandesompele J, Pattyn F, Hero B, Konig R, Fischer M, et al. Distinct transcriptional MYCN/c-MYC activities are associated with spontaneous regression or malignant progression in neuroblastomas. Genome Biol. 2008; 9: R150.

50. Williamson EA, Dadmanesh F, Koeffler HP. BRCA1 transactivates the cyclin-dependent kinase inhibitor p27(Kip1). Oncogene. 2002; 21:3199-3206.

51. Perini G, Diolaiti D, Porro A, Della Valle G. In vivo transcriptional regulation of $\mathrm{N}-\mathrm{Myc}$ target genes is controlled by E-box methylation. Proc Natl Acad Sci U S A. 2005; 102: 12117-12122.

52. London WB, Castleberry RP, Matthay KK, Look AT, Seeger RC, Shimada H, Thorner P, Brodeur G, Maris JM, Reynolds CP, Cohn SL. Evidence for an age cutoff greater than 365 days for neuroblastoma risk group stratification in the Children's Oncology Group. J Clin Oncol. 2005; 23 : 6459-6465. 